\title{
Metabolic profile and differentiation potential of extraembryonic endoderm-like cells
}

\author{
Mohamed I. Gatie (10 and Gregory M. Kelly (10 1,2,3,45
}

\begin{abstract}
Glucose metabolism has a crucial role for providing substrates required to generate ATP and regulate the epigenetic landscape. We reported that F9 embryonal carcinoma stem-like cells require cytosolic reactive oxygen species to differentiate into extraembryonic endoderm; however, mitochondrial sources were not examined. To extend these studies, we examined the metabolic profile of early and late-passage F9 cells, and show that their ability to differentiate is similar, even though each population has dramatically different metabolic profiles. Differentiated earlypassage cells relied on glycolysis, while differentiated late-passage cells transitioned towards oxidative phosphorylation (OXPHOS). Unexpectedly, electron transport chain protein stoichiometry was disrupted in differentiated late-passage cells, whereas genes encoding mitofusion 1 and 2, which promote mitochondrial fusion and favor OXPHOS, were upregulated in differentiated early-passage cells. Despite this, early-passage cells cultured under conditions to promote glycolysis showed enhanced differentiation, whereas promoting OXPHOS in latepassage cells showed a similar trend. Further analysis revealed that the distinct metabolic profiles seen between the two populations is largely associated with changes in genomic integrity, linking metabolism to passage number. Together, these results indicate that passaging has no effect on the potential for F9 cells to differentiate into extraembryonic endoderm; however, it does impact their metabolic profile. Thus, it is imperative to determine the molecular and metabolic status of a stem cell population before considering its utility as a therapeutic tool for regenerative medicine.
\end{abstract}

\section{Introduction}

Metabolism provides substrates for energy expenditure $^{1-3}$ and can modulate the epigenome, thereby influencing cell fate ${ }^{4-6}$. Typically, somatic cells rely on oxidative phosphorylation (OXPHOS) to generate ATP, whereas proliferative cancer and stem cells use glycolysis $^{7-11}$. ATP requirements in proliferative cells are high and, although OXPHOS is more efficient in generating

\footnotetext{
Correspondence: Gregory M. Kelly (gkelly@uwo.ca)

${ }^{1}$ Department of Biology, Collaborative Graduate Specialization in

Developmental Biology, The University of Western Ontario, London, ON,

Canada

${ }^{2}$ Department of Paediatrics, The University of Western Ontario, London, ON,

Canada

Full list of author information is available at the end of the article.

Edited by A. Rufini
}

ATP, sufficient glucose flux in glycolysis compensates for the rate of ATP production ${ }^{12-14}$. This categorization of metabolic profiles is distinct in early mammalian embryos $^{15}$. Naive embryonic stem cells (ESCs) use glycolysis and OXPHOS, whereas primed ESCs, having structurally mature mitochondria capable of OXPHOS, transition from bivalent metabolism to glycolysis ${ }^{16,17}$. Studies show that extraembryonic trophoblast stem cells preferentially use OXPHOS to produce $\mathrm{ATP}^{18}$. However, the metabolic profile of extraembryonic endoderm (XEN) stem cells, which differentiate into primitive (PrE) or parietal endoderm (PE) in a process recapitulated using F9 embryonal carcinoma stem-like cells (F9 cells), remains unknown $^{19-21}$. We reported that F9 cells require increased levels of cytosolic reactive oxygen species (ROS)

\section{(c) 2018 The Author(s).}

\footnotetext{
(c) Open Access This article is licensed under a Creative Commons Attribution 4.0 International License, which permits use, sharing, adaptation, distribution and reproduction cc) in any medium or format, as long as you give appropriate credit to the original author(s) and the source, provide a link to the Creative Commons license, and indicate if changes were made. The images or other third party material in this article are included in the article's Creative Commons license, unless indicated otherwise in a credit line to the material. If material is not included in the article's Creative Commons license and your intended use is not permitted by statutory regulation or exceeds the permitted use, you will need to obtain permission directly from the copyright holder. To view a copy of this license, visit http://creativecommons.org/licenses/by/4.0/.
} 
to differentiate into $\operatorname{PrE}^{22-24}$, but the role of the mitochondria, a major source of ROS, has not been investigated.

Mitochondria and metabolism have a key role in the reprogramming of somatic cells to induced pluripotent stem cells (iPSCs). These events require a metabolic transition from OXPHOS to glycolysis in order for cells to sustain proliferation and to reset the epigenetic landscape $^{25-27}$. The acquisition of pluripotency is not immediate as iPSCs that have undergone few passages share a molecular and epigenetic signature reminiscent of their somatic counterparts, whereas prolonged passaging resets their profile closer to $\mathrm{ESCs}^{28-30}$. However, and although not universal ${ }^{31,32}$, ESCs passaged extensively develop abnormal karyotypes, yet maintain pluripotency and differentiation potential ${ }^{33}$. Although studies have focused on the metabolic status of stem cells or the effects of passaging on their ability to differentiate, an understanding of how the two are linked is limited.

To address this, two populations of F9 cells were investigated and results show that early and late-passage cells had similar differentiation potential, but each have dramatically different metabolic profiles. These differences observed were due to changes in the expression and protein levels of pyruvate dehydrogenase (PDH) kinases (PDKs), which regulate the activity of PDH complex, thereby influencing the metabolic profile of cells. In addition, genes encoding mitochondrial fusion proteins were upregulated in early-passage F9 cells, while relative levels of mitochondrial electron transport chain (ETC) proteins were disrupted in late-passage cells. Surprisingly, culturing either cell population under their preferred metabolic conditions enhanced the exit from pluripotency and promoted PrE formation. More importantly, latepassage cells possessed an abnormal karyotype, resulting in increased proliferation rates, which were correlated to significant increases in the expression of cell cycle regulators. Together, these results demonstrate that early- vs. late-passage F9 cells retain their ability to differentiate into XEN; however, this ability to occur in cells that have different metabolic profiles and chromosomal composition, underpins the importance of monitoring the physiology of stem cell populations to ensure their quality as a tool for regenerative medicine.

\section{Results}

\section{Late-passage F9 cells differentiate to XEN-like cells}

Undifferentiated late-passage F9 cells grew in compact colonies, while those induced to form PrE or PE adopted a stellate-like phenotype (Fig. S1A). Oct4 expression in RAinduced PrE was similar to controls (Fig. S1B), but protein levels were reduced significantly (Fig. S1F, G). This was more dramatic in cells induced to PE by $R A$ and $d b-$ cAMP (RDB; Fig. S1B, F, G). Increased expression of
Gata6 and Dab2 (Fig. S1C, D, respectively), and levels of DAB2 (Fig. S1F, H) and KERATIN-8 (Fig. S1F, I) were evidence that F9 cells had differentiated into PrE. Finally, significant increases in Thrombomodulin (Thbd) expression (Fig. S1E) and in THBD levels (Fig. S1F, J) indicated that cells had differentiated to PE. Collectively, these results support the findings that F9 cells differentiated to PrE and PE-like lineages when treated with RA and RDB, respectively ${ }^{20,21}$.

\section{Mitochondrial activity during late-passage differentiation}

Although ROS generated from cytoplasmic sources accompanies F9 cell differentiation ${ }^{22-24}$, mitochondrial sources were never examined. To address this, latepassage F9 cells were treated with DMSO-, RA-, or RDB, and then stained with MitoSOX to detect mitochondrial superoxide (Fig. 1a-c) or with TMRM for mitochondrial activity (Fig. 1e-g). PrE cells showed a significant increase in mitochondrial superoxide levels relative to controls (Fig. 1d), but not mitochondrial activity (Fig. 1h). Significant differences in superoxide levels and mitochondrial activity were also noted in PE cells (Fig. 1d, h, respectively). These changes suggested that differentiation was accompanied by an increase in OXPHOS, which was supported by the increase in ATP levels in these cells (Fig. 1i). Cells were also assayed for changes in metabolites in the media, and results showed that overall, a significant decrease in glucose uptake (Fig. 1j), but not lactate production (Fig. 1k) occurred in PrE cells. To examine if these changes were due to altered expression of glucose transporters ${ }^{35}$, cells were differentiated, and then assayed for Glut1-4, 8, and 9 (Fig. S2). Glut1, 3, and 9 expression increased significantly in PrE, whereas Glut3 and 9 were significantly upregulated in PE. Conversely, Glut4 transcript abundance decreased in PrE, whereas Glut2 and 8 expression remained unchanged. These results suggested that GLUT4 is likely the key glucose transporter during RA-induced differentiation of latepassage F9 cells.

\section{Metabolic changes accompanying late-passage differentiation}

To examine the metabolic profile, late-passage F9 cells were differentiated and then analyzed to detect transcripts encoding Lactate dehydrogenase A (LDHA), which promotes the conversion of pyruvate to lactate, and LDHB, which catalyzes the reverse reaction. $L d h a$ expression was significantly downregulated in PrE and PE cells (Fig. 2a), but only in PE cells at the protein level (Fig. 2c, d). However, $L d h b$ transcripts were only significantly downregulated in PrE (Fig. 2a) and a similar trend was seen at the protein level (Fig. 2c, e). The expressions of Pdk1-4 (Fig. 2b), which encode PDK isoforms that phosphorylate and inactivate the PDH complex, were examined (Fig. 2b). 


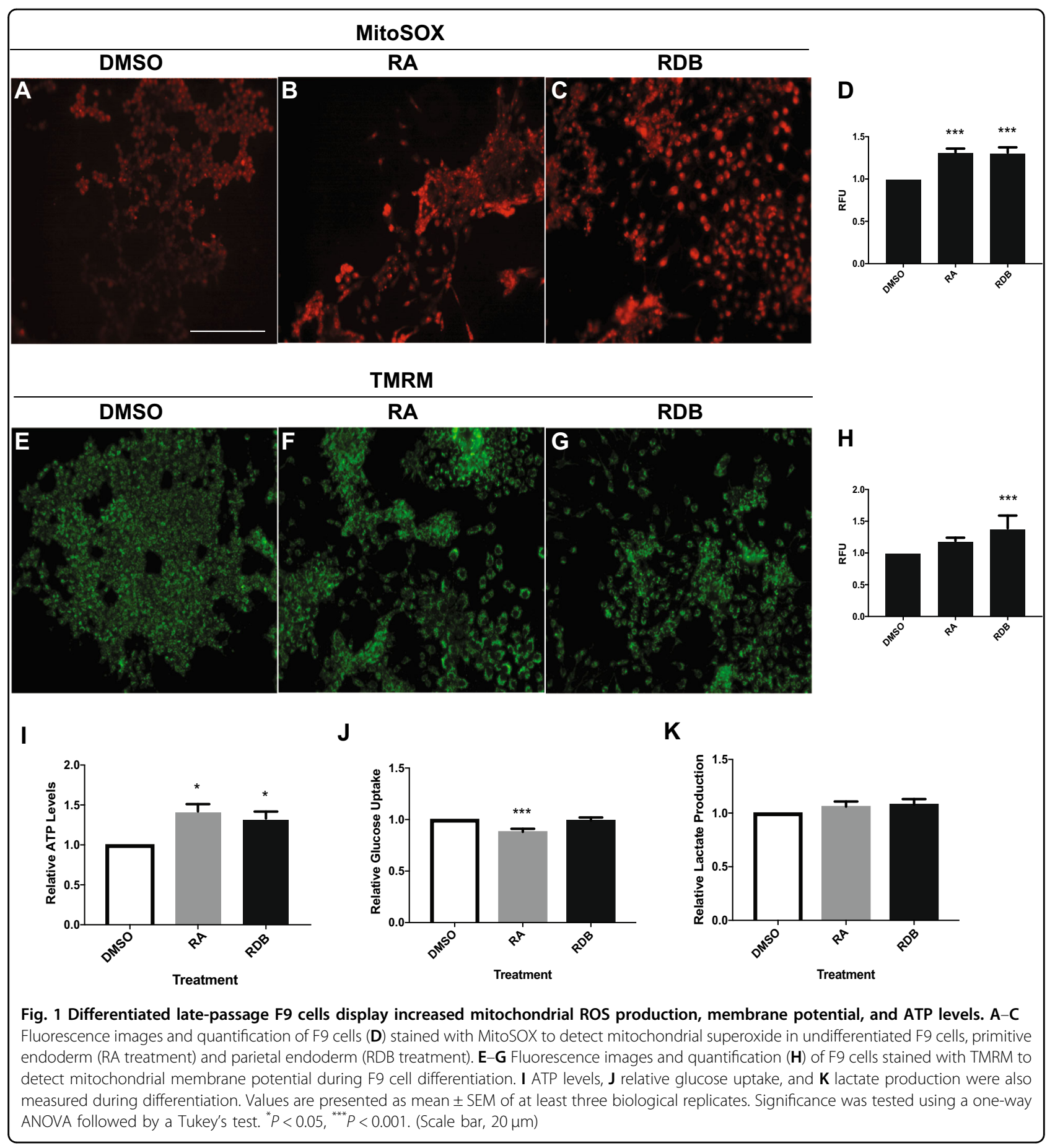

Results show that $P d k 1$ was significantly downregulated during differentiation, whereas $P d k 2$ was significantly upregulated relative to controls (Fig. 2b). Similar results were seen at the protein level (Fig. 2f, g, h). Despite these increases, PDH-E1 $\alpha^{\mathrm{pSer} 232}$ (Fig. 2f, i) and PDH-E1 $\alpha^{\mathrm{pSer} 293}$ (Fig. 2f, j) levels were reduced significantly, suggesting that PDK1 likely regulates the activity of the PDH complex during differentiation.
To further examine the role of PDK1 in PrE differentiation, Pdk1-expressing stable lines were generated (Fig. 3). As expected, clones overexpressing PDK1 showed significantly higher levels of $P d k 1$ expression (Fig. 3a) and protein levels (Fig. 3e, f) over controls. To test the functionality of the exogenous PDK1, PDH-E1 $\alpha^{\mathrm{PSer} 232}$ was assayed and results show its levels were significantly higher than those in controls (Fig. 3e, g). Next, Oct4 


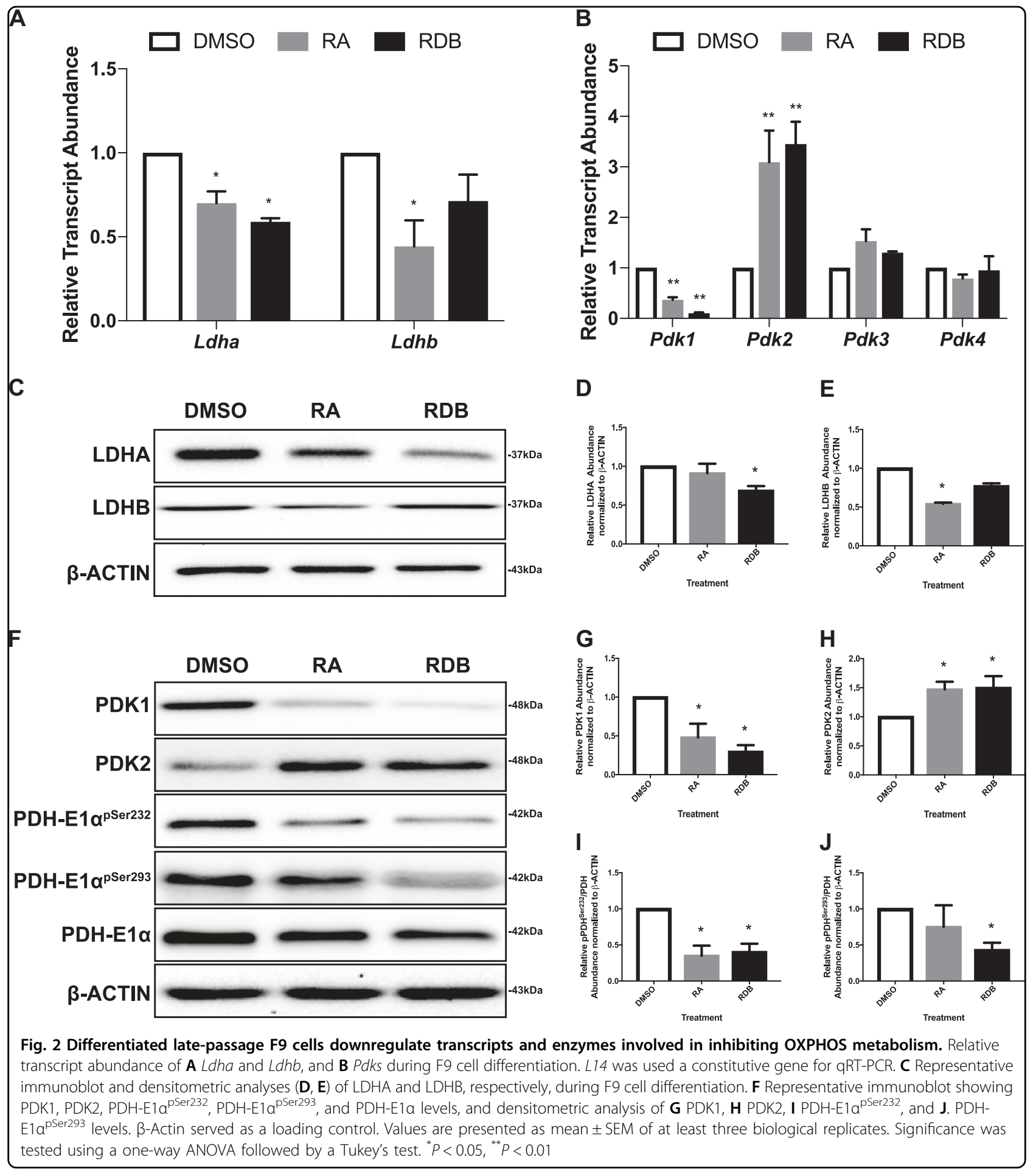

expression and protein levels were examined and found to be reduced significantly in control cells treated with RA (Figs. 3b, h, respectively), but neither were affected by RA in PDK1-overexpressing cells (Fig. 3b, h). Despite seeing changes in OCT4 levels between the two clones, Gata6 expression did not differ (Fig. 3c). However, although Dab2 expression was significantly upregulated in control
PrE cells, there was no significant difference when compared to Pdk1-overexpressing cells (Fig. 3d). In converse, DAB2 protein levels were significantly lower when $P d k 1$ was overexpressed (Fig. 3i). Lastly, overexpressing Pdk1 attenuated RA-induced PrE differentiation as evident by the levels of KERATIN-8, which were not significantly different from controls (Fig. 3j). Together, these results 
A

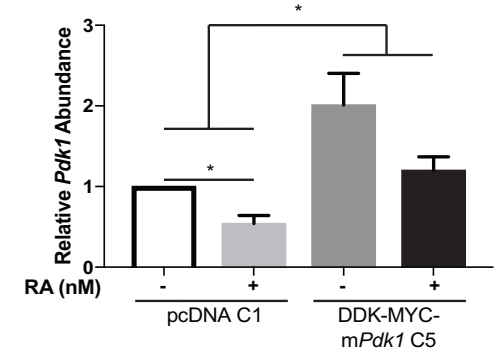

C

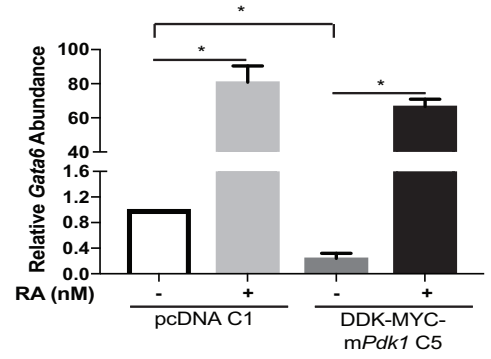

E

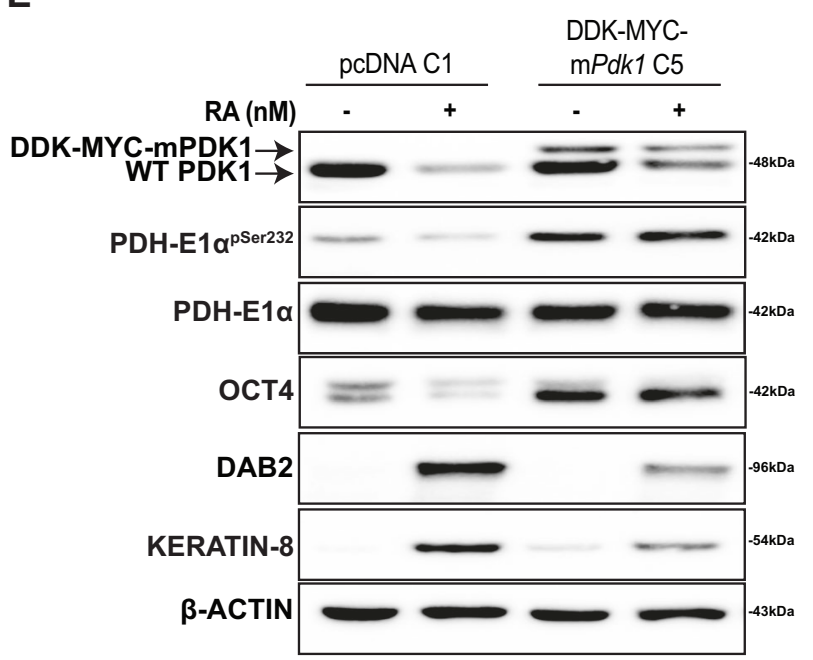

B

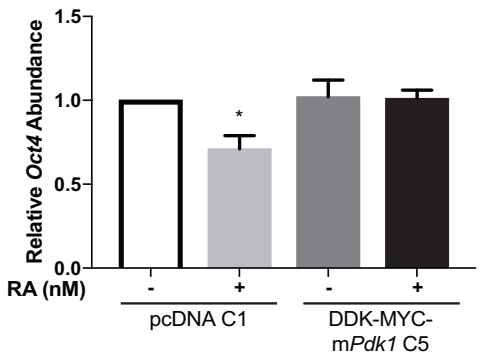

D

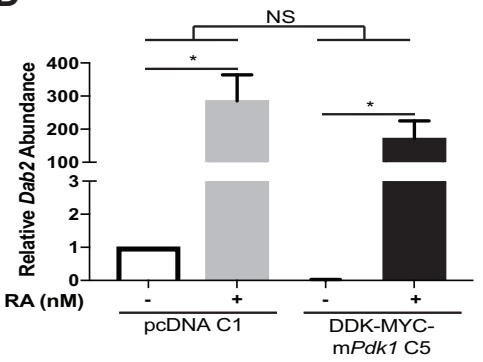

$F$

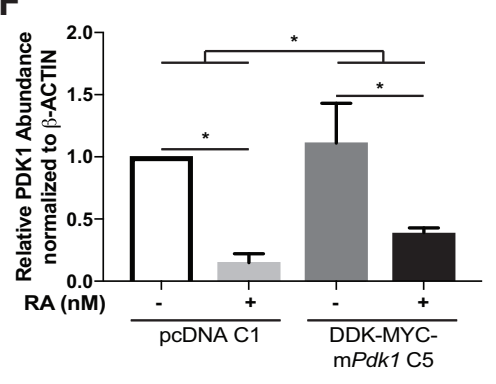

G

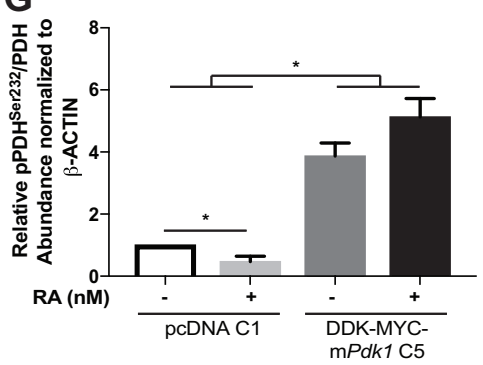

H

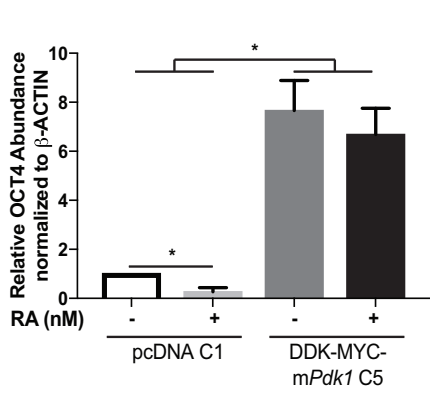

I

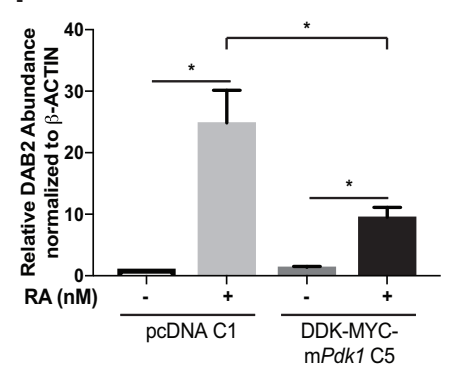

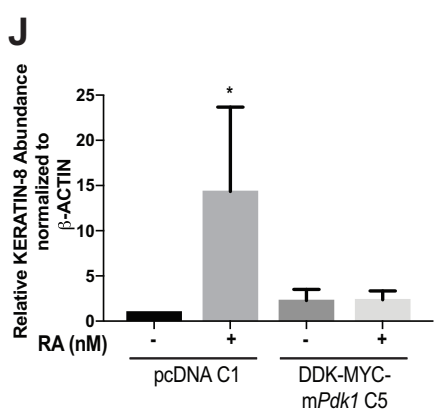

Fig. 3 (See legend on next page.) 
(see figure on previous page)

Fig. 3 Overexpression of PDK1 attenuates RA-induced differentiation of late-passage F9 cells. qRT-PCR of relative abundance of A Pdk1, B Oct4, C Gata6, and D Dab2 in pcDNA 3.1 clone 1 (pcDNA C1) or DDK-MYC-mPDK1 clone 5 (DDK-MYC-mPDK1 C5)-overexpressing F9 cells treated with DMSO or RA for $96 \mathrm{~h}$. L14 was used a constitutive gene for qRT-PCR. Representative immunoblot (E) and densitometric analysis of F PDK1, G PDH$\mathrm{E}_{1} \mathrm{a}^{\mathrm{pSer} 232}$, H OCT4, I DAB2, and J KERATIN-8 in pCDNA C1 or DDK-MYC-mPDK1 C5-overexpressing F9 cells treated with DMSO or RA for $96 \mathrm{~h}$. $\beta$-Actin served as a loading control. Values are presented as mean \pm SEM of at least three biological replicates. Significance was tested using a one-way ANOVA followed by a Tukey's test. ${ }^{*} P<0.05$

indicate that the overexpression of $P d k 1$, and inactivation of the PDH complex in F9 cells, maintains pluripotency and reduces the differentiation potential.

\section{Passaging alters metabolism but not differentiation potential}

As passage number influences stem cell quality and fate ${ }^{36-40}$, we asked whether F9 cells at early passages $(<20)$ exhibited a differentiation and metabolic profile similar to that in late-passage cells. Examining markers of differentiation (Gata6, Dab2, and Thbd) showed similar expression profiles between the two populations (Fig. S3ac). Similarly, OCT4 levels were higher in the undifferentiated state, and KERATIN-8 levels higher in the differentiated state (Fig. S3d-f). Thus, early- and late-passage F9 cells exhibited similar differentiation profiles, and it was expected that the metabolic profiles would be similar. To test this, the expression of $L d h$ transcripts and the levels of protein were examined (Fig. S4A and Fig. S4B, C, respectively). No significant differences in the abundance of $L d h a$ and $L d h b$ were detected in early-passage cells, and at the protein level, both levels were significantly reduced by RDB (Fig. S4B, C). Differences were seen, however, in the expression of Pdks, and while the decreasing Pdk1 trend with differentiation was maintained between the two populations (Fig. $4 \mathrm{a}$ and Fig. 2b, respectively), $P d k 3$ and $P d k 4$ expression was upregulated significantly only in early-passage cells (Fig. 4a). No significant difference in the abundance of $P d k 2$ was evident in early-passage cells (Fig. 4a), which contrasts that seen in late-passage cells (Fig. 2b). At the protein level, PDK1 levels dropped significantly with differentiation (Fig. 4b, c), while PDK4 levels increased significantly in PE (Fig. 4b, e). Despite the increase in Pdk3 expression (Fig. 4a), PDK3 levels remained unchanged in differentiated early-passage cells (Fig. 4b, d). These differences in PDK profiles prompted further investigation into the phosphorylation status of PDH-E1 $\alpha^{\mathrm{pSer} 293}$, which in late-passage F9 cells decreased with differentiation (Fig. 2f, k). In early-passage cells, PDH-E1 $\alpha^{\mathrm{pSer}^{\mathrm{2} 93}}$ levels increased significantly, but only in PE (Fig. 4b, f). To explain the increase, PDH phosphatases (PDPs), which dephosphorylate serine residues and subsequently activate the PDH complex, were examined (Fig. 4g). Results show $P d p 1$ and $P d p 2$ expression was significantly downregulated in response to RA treatment, but only in early-passage cells, suggesting that the increase in PDH-E1 $\alpha^{\mathrm{pSer293}}$ levels is due to PDK4. To test whether the PDH complex was inactive, lactate levels in the media and glucose uptake were measured in early-passage undifferentiating and differentiated cells (Fig. 4h, i, respectively). Media from PE cells showed significantly more lactate (Fig. 4h) when compared to controls, and this was accompanied by a significant increase in glucose uptake (Fig. 4i). The relative abundance of Glut1-4, 8 and 9 in early-passage F9 cells was also examined, and while Glut1 and 3 expression was significantly upregulated in $\operatorname{PrE}$, Glut2, and 4 expression were only upregulated significantly in PE (Fig. S5). Glut8 expression was downregulated significantly in $\operatorname{PrE}$ (Fig. S5), unlike that seen in late-passage cells (Fig. S2). Collectively, the results indicate that unlike late-passage F9 cells, those that have not been passaged extensively transition from OXPHOS metabolism toward glycolysis during differentiation.

\section{Mitochondrial dynamics in early- vs. late-passage cells}

As uncoupling proteins, which have been implicated in regulating stem cell differentiation ${ }^{41,42}$, showed no difference between the two populations (Vorobieva and Kelly, unpublished), the focus turned to ETC proteins. Analysis revealed that undifferentiated and differentiated early-passage cells express comparable levels of all ETC subunits, with the exception of succinate dehydrogenase complex iron sulfur subunit B (SDHB) in complex II (Fig. 5a, b). Differentiation of late-passage cells to PrE or PE caused a significant decrease in the levels of MTCO1 (complex IV), SDHB (complex II), and NDUFB8 (complex I; Fig. 5c, d). In order to explain the disruption of ETC proteins, the expression profiles of genes involved in mitochondrial fission and fusion were examined. Earlypassage cells showed no significant change in Drp1, Opa1, and Fis1 expression, which encode proteins that promote mitochondrial fission; however, $M f n 1$ and 2 expression was significantly upregulated in PE (Fig. 5e). No obvious changes were detected in late-passage cells (Fig. 5f), and despite seeing elevated mitochondrial ROS levels and increased activity in differentiated late-passage cells (Fig. 1a-h), the data suggests that the mitochondria in both early and late-passage cells are mature, fused and capable of OXPHOS metabolism. 


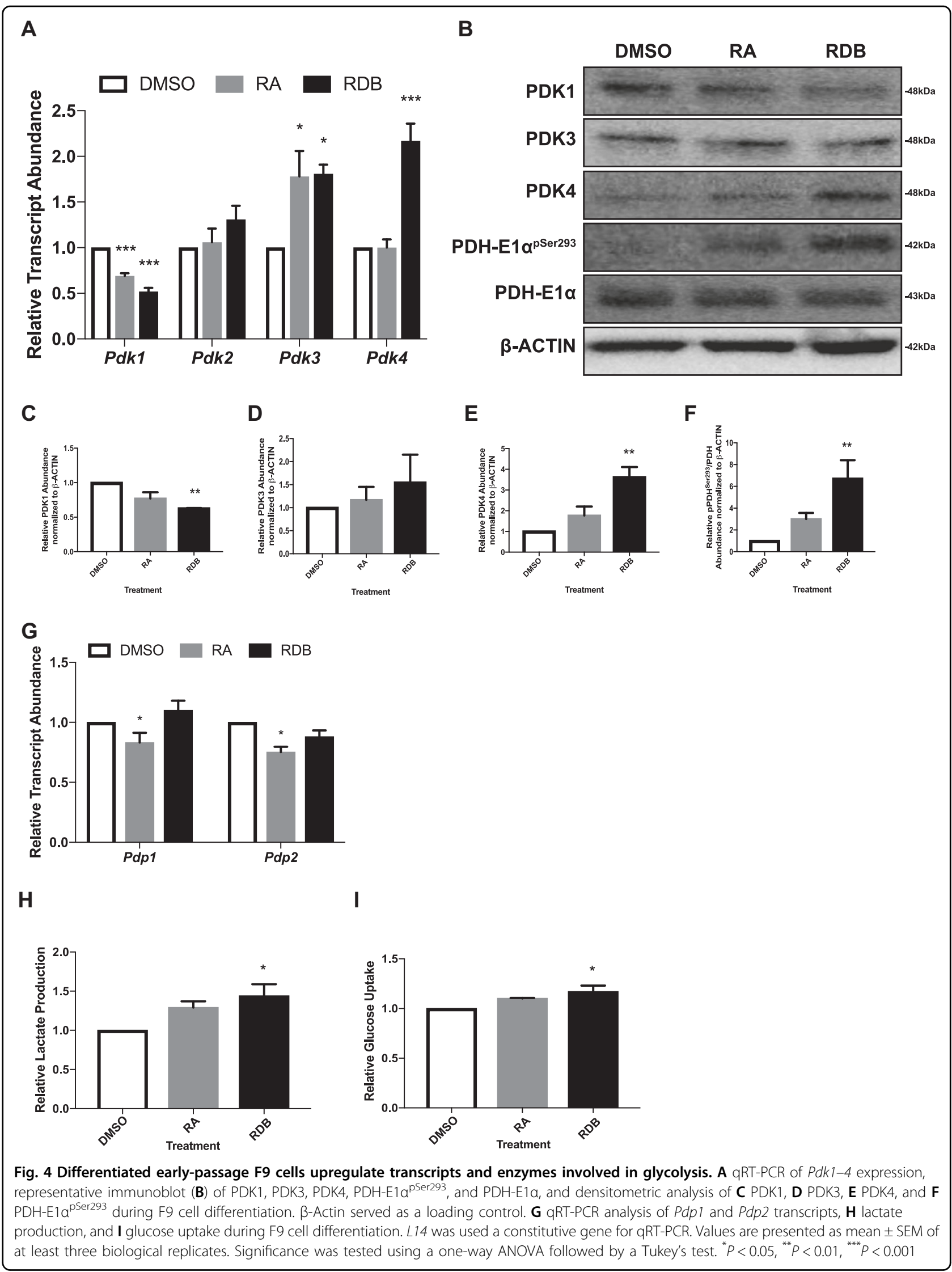




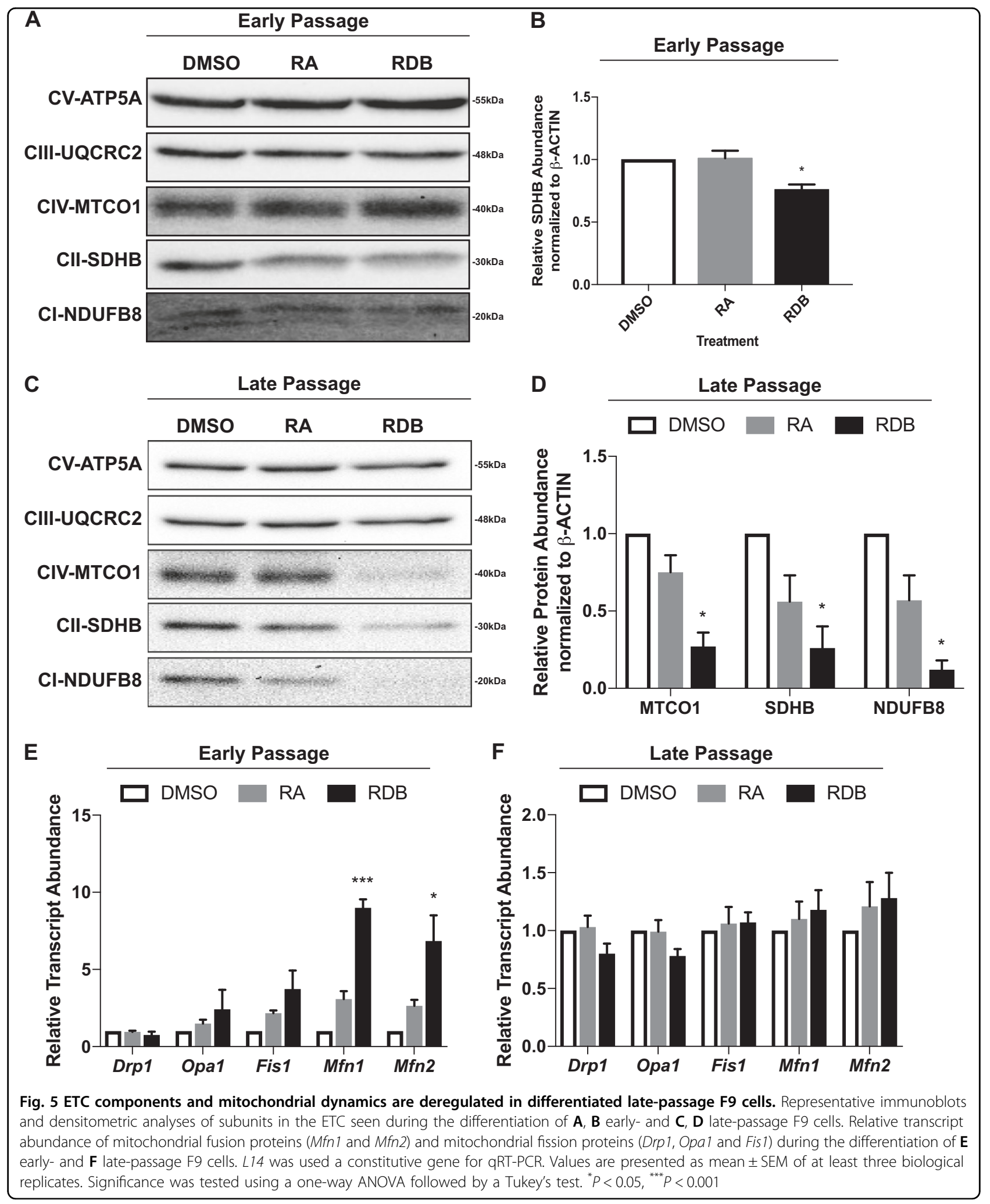




\section{Glycolysis promotes differentiation of early-passage F9 cells}

If early-passage F9 cells transition towards glycolysis during differentiation, then promoting glycolysis in these cells should induce differentiation. To test this, earlypassage cells were treated with UK5099, a noncompetitive inhibitor of the mitochondrial pyruvate uptake transporter. Concentrations between 0.05 and 5 $\mu \mathrm{M}$ had no apparent effect on cell viability compared to the control (data not shown). A $5 \mu \mathrm{M}$ concentration was selected, and results show that treatment in combination with RA caused a significant reduction in the abundance of Oct4 relative to RA alone (Fig. 6a). Although these results suggested cells were exiting the pluripotent state,

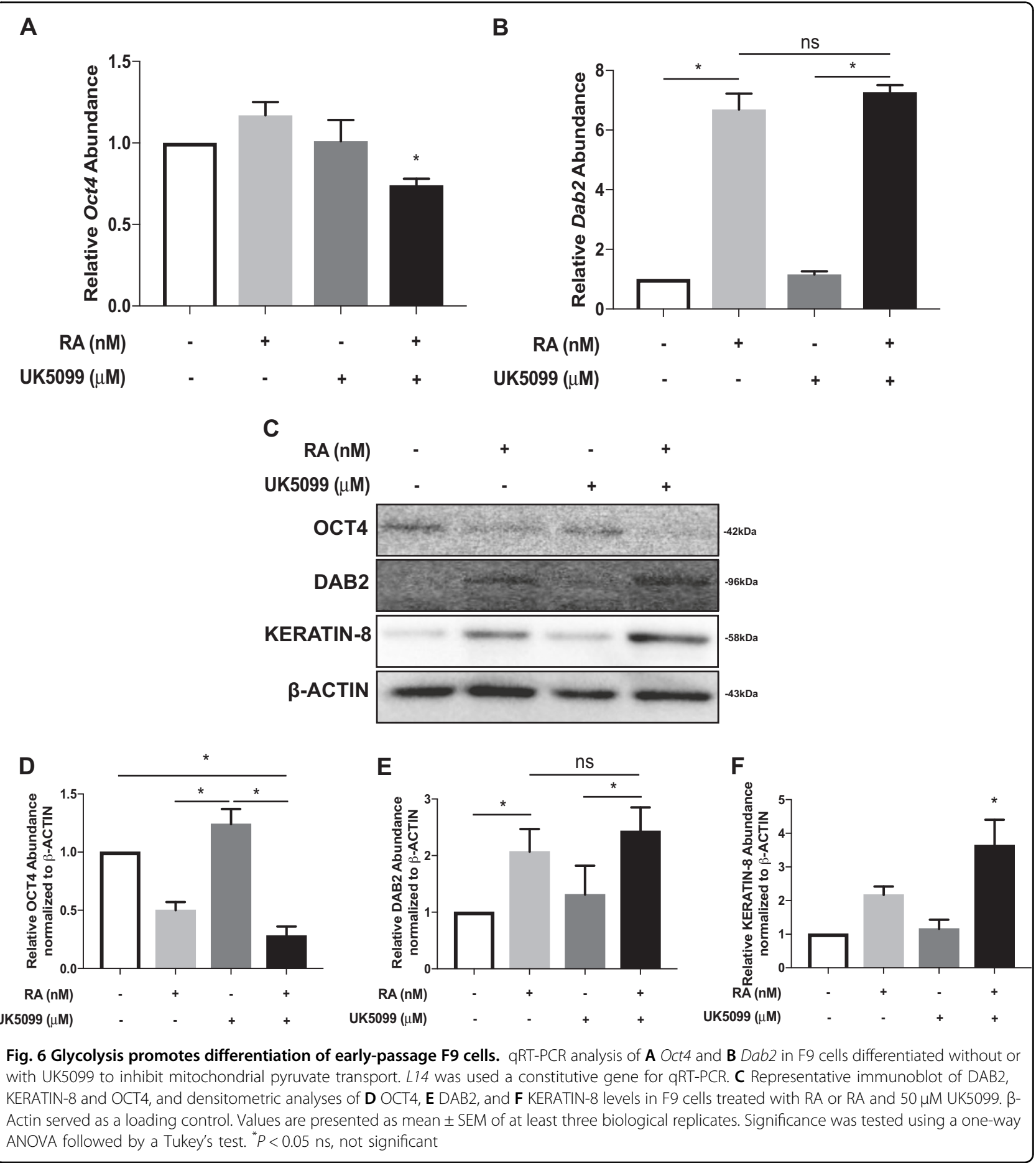


treatment alone or in combination with RA showed no additive effects on Dab2 expression (Fig. 6b). OCT4, DAB2, and KERATIN-8 levels were also analyzed, and as expected OCT4 levels were significantly lower in RAtreated cells, and even lower in the treatment with UK5099 (Fig. 6c, d). DAB2 levels, similar to the corresponding expression data, were not significantly different between RA or RA and UK5099 treatments (Fig. 6c, e); however, under the same conditions, KERATIN-8 levels were significantly higher (Fig. 6c, f). Thus, culturing earlypassage cells under conditions to promote glycolysis enhanced the exit from pluripotency and differentiation to PrE.

\section{OXPHOS enhances the exit of pluripotency in late-passage cells}

As promoting glycolysis in early-passage F9 cells enhanced their ability to differentiate, then promoting OXPHOS in late-passage cells should augment differentiation. To test this hypothesis, late-passage cells were cultured in increasing concentrations of DCA, a competitive PDK inhibitor, and then assayed for changes in metabolism and differentiation (Fig. 7). Cells cultured in the highest concentration of DCA $(6 \mathrm{mM})$ showed a significant reduction in cell viability $(88 \pm 1 \%$; Fig. 7 a); however, $6 \mathrm{mM}$ DCA was selected, as it caused the most significant reduction in PDH-E $1 \alpha^{\mathrm{pSer} 232}$ and $\mathrm{PDH}-$ E1 $\alpha^{\text {PSer293 }}$ levels (Fig. 7b-d), resulting in significantly higher ATP levels (Fig. 7e). As for differentiation, DAB2 and KERATIN-8 levels were significantly higher than the controls, but only in cells co-treated with RA and DCA (Fig. 7f, g and Fig. 7f, h, respectively). As the results would indicate that cell differentiation was augmented by DCA, OCT4 levels in the cells should be dramatically decreased. This was tested and results show OCT4 levels were significantly reduced in RA-treated cells relative to controls (Fig. 7f, i). As expected, these levels were even more reduced in cells treated with RA and DCA (Fig. 7f, i), suggesting that promoting OXPHOS in late-passage cells not only enhanced their exit from pluripotency, but it also promoted their differentiation.

\section{Genomic integrity and cell cycle regulation in early- vs. late-passage cells}

Although metabolic changes can influence genomic integrity ${ }^{43}$, reports have shown that extensive passaging of adherent cells and ESCs can induce genetic abnormalities thereby affecting cellular metabolism ${ }^{44,45}$. To address this, karyotyping was used to determine whether chromosomal composition could explain the variations observed between early and late-passage cells. Analysis revealed approximately $60 \%$ of the early-passage F9 cells have the proper karyotype, while less than $5 \%$ of the late-passage F9 cells had the optimal chromosome number (Fig. 8a).
Furthermore, the chromosome frequency distribution of early-passage cells was significantly different from the late-passage cells $\left(\chi^{2}=42.868, \mathrm{df}=2, P<0.001\right.$, Fig. $\left.8 \mathrm{~b}\right)$. Cell proliferation was examined as this is known to be affected by chromosomal abnormalities ${ }^{46}$. Results showed early-passage cells proliferated at a significantly lower rate than late-passage cells (Fig. 8c). An examination of various cell cycle regulators including Cdkn1a, Cdkn1b, $C d k n 2 a, C d k n 2 c, C d k n 2 d, C c n d 1, C d k 4, C d k 6, P 53$, and $R b 1$ revealed that with the exception of $C d k n 2 a$, the other cell cycle markers were upregulated in late-passage cells (Fig. 8d). Together, this loss of genomic integrity could account for the differences in the proliferation rates and metabolic profiles seen between early- vs. late-passage cells.

\section{Discussion}

Stem cells hold great potential for regenerative medicine applications; however, understanding their physiology in vitro is crucial to ensure the delivery of quality cells to patients. We used F9 cells to determine the metabolic profile during XEN-like differentiation, and how passaging may affect their metabolic profile and differentiation potential. Two cell populations were examined and although each differentiated and upregulated markers of PrE and PE (Figs. S1, 3), their metabolic profiles differed dramatically. During differentiation, latepassage F9 cells transitioned from glycolysis to OXPHOS resulting in an increase in mitochondrial ROS levels and mitochondrial activity, both correlated with increased ATP production (Fig. 1). The increase in OXPHOS during differentiation is explained by the reduction in PDK1 levels (Fig. 2f, g), resulting in reduced

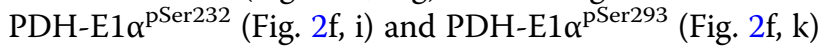
levels. Conversely, overexpressing Pdk1 attenuated RAinduced differentiation in these cells (Fig. 3). A similar trend occurs with iPSCs, human ESCs (hESCs), and mesenchymal stem cells (MSCs), which are glycolytic in nature due to an inactive PDH complex shuttling pyruvate to lactate ${ }^{25,26}$, but employ OXPHOS when differentiated $^{27,47,48}$. The opposite scenario occurs in the mouse early embryo as naïve ESCs exhibit bivalent metabolism, while differentiated primed ESCs use glycolysis ${ }^{16}$, similar to differentiated early-passage cells as they increased lactate production (Fig. 4g), with elevated levels of PDK4 (Fig. 4b, e), and concomitant increased levels of PDH-E1 $\alpha^{\text {pSer293 }}$ (Fig. 4b, f). During the differentiation of adult stem cells, elevated lactate levels and subsequent increased Acetyl-CoA levels enhance histone H3K9 acetylation, a prelude required for differentiation ${ }^{49}$. However, this is not universal, and the fact that other stem cells transition towards OXPHOS when they differentiate $^{50}$, highlight cell-specific differences regulated by the intricacies of the metabolome. 
A

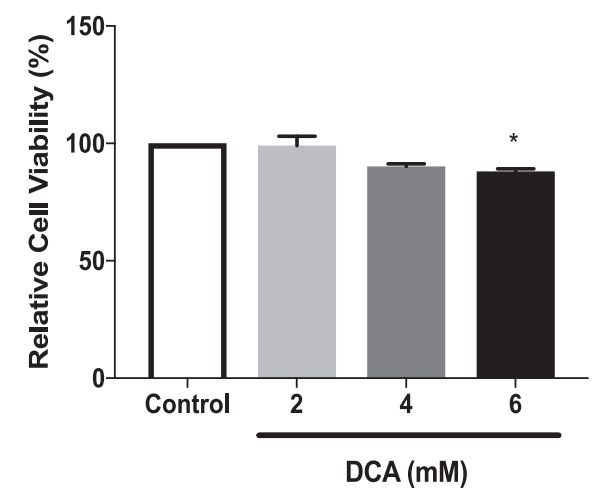

B

DCA (mM)

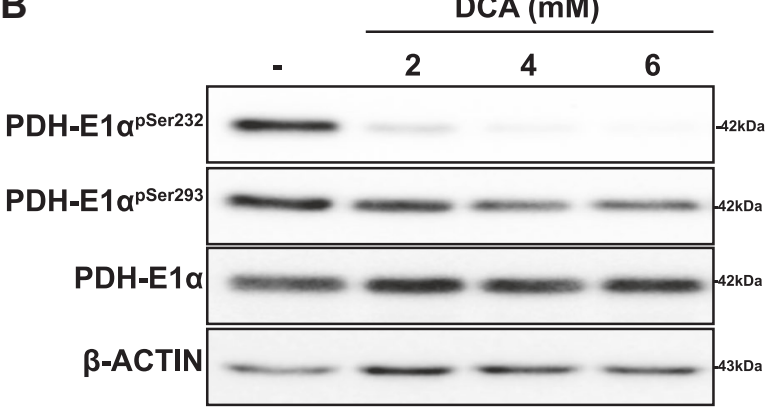

C

D
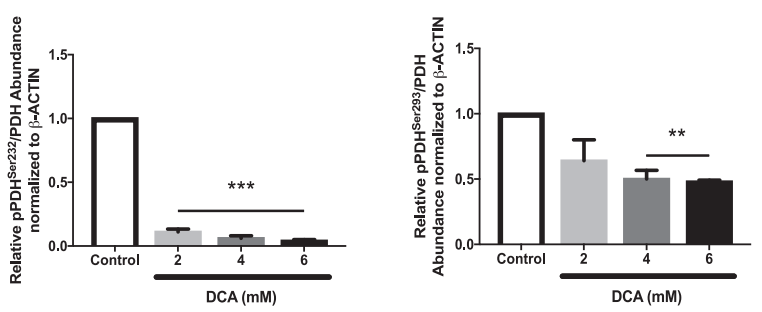

E

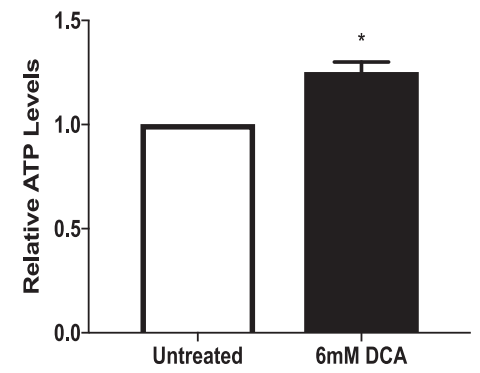

F

G
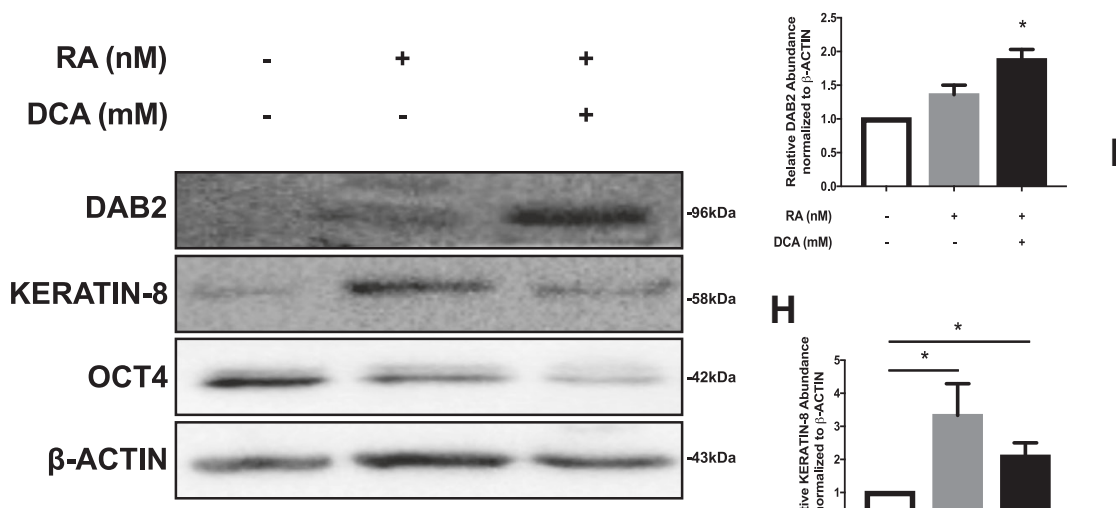

$\mathrm{H}$

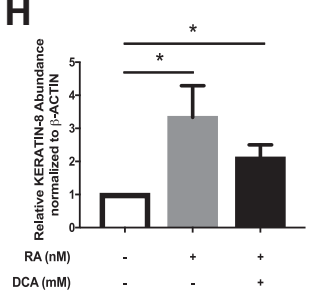

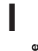

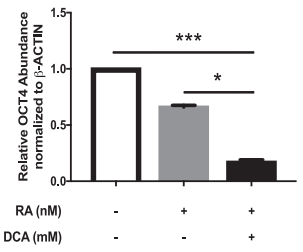

$\mathrm{DCA}(\mathrm{mM})$

Fig. 7 (See legend on next page.) 
(see figure on previous page)

Fig. 7 OXPHOS promotes differentiation of late-passage F9 cells. A MTT viability assay, representative immunoblot (B) of PDH-E1a $a^{\text {pSer232, } P D H-~}$

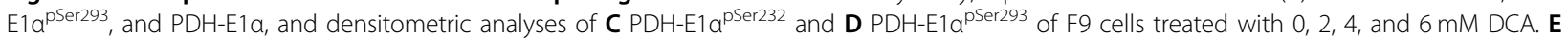
Relative ATP levels in untreated and $6 \mathrm{mM}$ DCA-treated F9 cells. F Representative immunoblot of DAB2, KERATIN-8, and OCT4, and densitometric analyses of $\mathbf{G}$ DAB2, $\mathbf{H}$ KERATIN-8, and I OCT4 in F9 cells treated with RA or RA and 6 mM DCA. $\beta$-Actin served as a loading control. Values are presented as mean \pm SEM of at least three biological replicates. Significance was tested using a one-way ANOVA followed by a Tukey's test. ${ }^{*} P<0.05$, ${ }^{* *} P<0.01,{ }^{* * *} P<0.001$

A

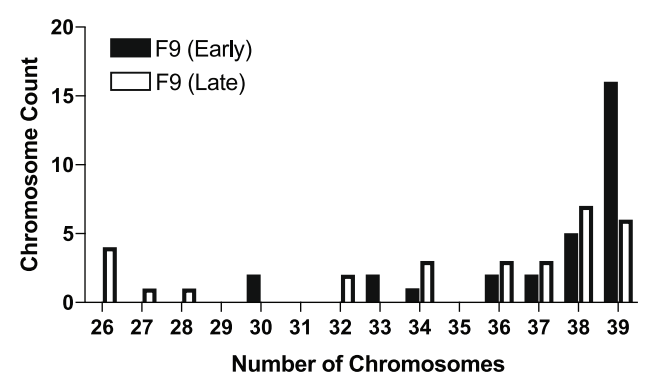

C

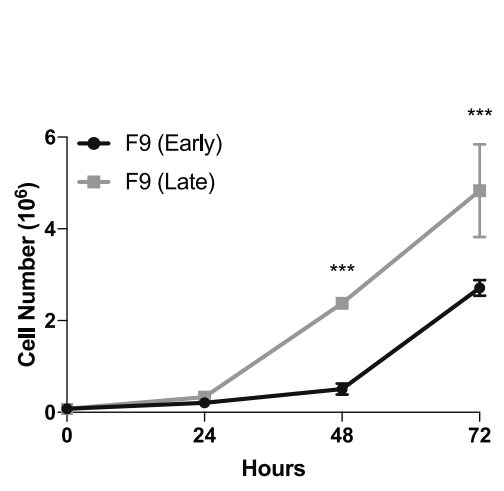

B

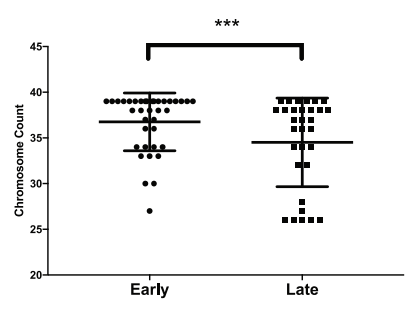

D

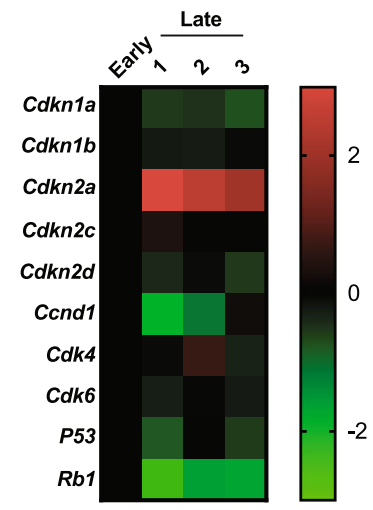

$\mathbf{E}$

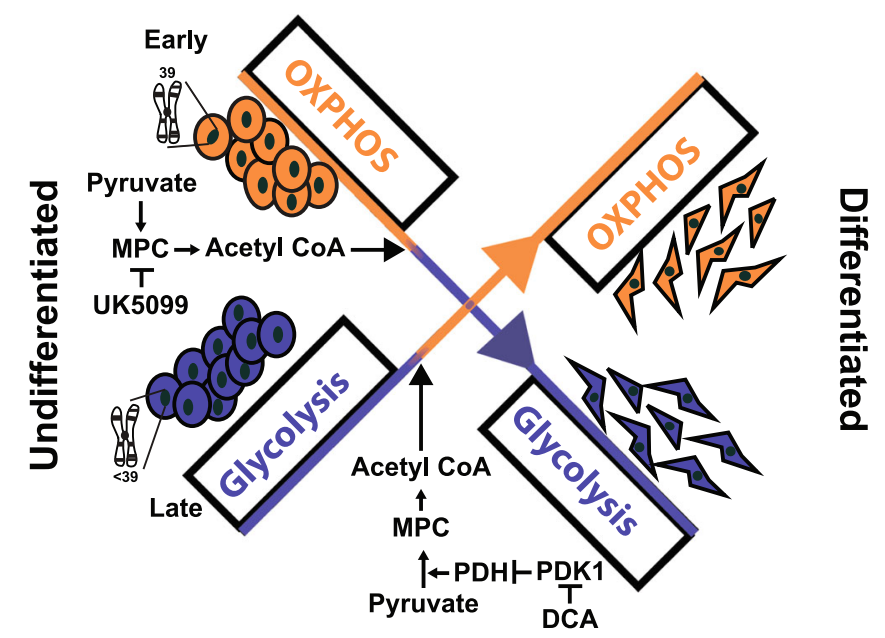

Fig. 8 Early-passage F9 cells display a genetically stable karyotype and proliferate slower than late-passage F9 cells. a Number of chromosome, $\mathbf{b}$ chromosomal frequency, and $\mathbf{c}$ growth curve of early and late-passage F9 cells. $\mathbf{d}$ Differential expression of genes encoding proteins involved in cell cycle regulation and progression between early- vs. late-passage F9 cells. e Schematic overview of the mechanisms regulating metabolism in both populations. Values are presented as mean \pm SEM of at least three biological replicates. Significance was tested using a one-way ANOVA followed by a Tukey's test. Chromosomal distribution frequency was tested by $x^{2}$-test for the Goodness of Fit. ${ }^{* * *} P<0.001$ 
The metabolome is directly affected by the mitochondria $^{51}$, whose activity is linked to substrate availability and structure $^{52}$. ETC protein stoichiometry dictates the flow of electrons, which influences mitochondrial activity ${ }^{53}$. As described earlier, iPSCs upregulate glycolytic enzymes during the early stages of reprogramming ${ }^{26,27}$ and this coincides with the downregulation of proteins in complex I and IV, and the upregulation of proteins in complex II, III and $\mathrm{V}^{54}$. Although the metabolic profile of iPSCs is similar to differentiated early-passage cells, there were no detectable changes to complex I and IV in these cells (Fig. 5a, b). In contrast, the reduction in protein levels in these complexes were seen in differentiated late-passage cells, which favor OXPHOS during differentiation (Fig. 5c, d). Nevertheless, the disruption of ETC stoichiometry in late-passage cells explains the elevation in mitochondrial ROS (Fig. $1 \mathrm{a}-\mathrm{d}$ ), which together with cytosolic sources, activate the canonical $\mathrm{WNT} / \beta$-catenin pathway required for F9 cell differentiation ${ }^{22-24}$. Surprisingly, these elevated mitochondrial ROS levels were not accompanied by changes in the levels of mitochondrial dynamic proteins (Fig. 5f) that are typically associated with mitochondria actively generating $\mathrm{ATP}^{55}$. Instead, an increase in the expression of $M f n 1$ and $M f n 2$, which encode mitochondrial fusion-promoting proteins, was seen in differentiated early-passage cells (Fig. 5e). Similarities exist with primed ESCs and hESCs, which possess oval-shaped mitochondria with dense matrix, prominent cristae, and high mtDNA copy number, but have reduced mitochondrial respiration rates due to deficiencies in in complex $I$ and $I V^{16}$. These inconsistencies in the literature confounded the interpretation of our data and details to explain the differences in metabolic profile seen between early- vs. late-passaged F9 cells led us to examine other possibilities.

Genomic integrity was one possible explanation, as long-term passaging of stem cells can promote chromosomal abnormalities resulting in loss of pluripotency and low contribution to chimeras ${ }^{32}$. In our report, early- and late-passage F9 cells shared similar pluripotency and differentiation profiles (Fig. S1, S3); however, based on a comparison with other stem cell lines, we were unable to assign candidates that would implicate their involvement in the metabolic differences seen in the two F9 cell populations. It is known that mESC lines cultured for prolonged periods develop abnormal karyotypes, yet maintain pluripotency and differentiate when grown as embryoid bodies $^{33}$. Our results revealed dramatic differences in the karyotypes of early- and late-passage F9 cells (Fig. 8a, b), and these would have profound effects on the physiology of each population. Differences included altered levels of ROS (Fig. 1a-d) and elevated CDKNA1 and p53 levels (Fig. 8d), the latter affecting the proliferation rate in late-passage F9 cells (Fig. 8c). Interestingly, these characteristics are seen in late-passage $\mathrm{MSCs}^{47}$ and hESCs $^{56}$, and although they are attributed to abnormal karyotypes, other cell lines retain proper chromosomal composition and show no apparent change in cell proliferation rate or pluripotency potential ${ }^{56}$. Thus, like earlyand late-passage F9 cells, stem cells have properties that may or may not change with passaging, suggesting that culturing methods and passage number are not the only factors promoting chromosomal degradation ${ }^{57}$.

Overall, our results clearly demonstrate that early versus late-passage F9 cells have the ability to differentiate into XEN, but they do so using different metabolic profiles (Fig. 8e). Moreover, culturing either population under conditions that favor their profile enhances their exit from pluripotency and promoted differentiation. Although several reports have documented the differentiation of F9 cells into PrE ${ }^{58-63}$, none have addressed the mechanisms in reference to metabolic profile or altered karyotypes that accompany extensive passaging. Thus, the desired differentiation phenotype of cells may come at a cost if genomic integrity is compromised. Furthermore, this underpins the importance of continually scrutinizing a stem cell population to ensure best practices for regenerative therapies.

\section{Materials and methods \\ Cell culturing conditions}

F9 embryonal carcinoma stem-like cells (Sigma) were cultured at $37{ }^{\circ} \mathrm{C}$ and $5 \% \mathrm{CO}_{2}$ on $0.1 \%$ gelatin-coated plates in Dulbecco's modified Eagle's medium (Lonza) supplemented with $10 \%$ heat-inactivated fetal bovine serum (Thermo Fisher Scientific) and 1\% penicillin-streptomycin (Thermo Fisher Scientific). All cultures were tested for mycoplasma ${ }^{34}$ and cells under 20 passages were classified as being early. To induce PrE differentiation, cells were treated daily for $72 \mathrm{~h}$ with 100 nM All-trans retinoic acid (RA; Sigma), or treated daily with $100 \mathrm{nM}$ RA and $10 \mathrm{mM}$ db-cAMP (RDB; Sigma) to induce PE. Cells treated with dimethyl sulfoxide (DMSO) served as a negative control.

\section{Generation of PDK1-stable cell line}

F9 cells were plated as described above and reverse transfected using Lipfectamine 2000 (Thermo Fisher Scientific). Briefly, 200,000 cells were seeded in $35 \mathrm{~mm}$ gelatin-coated plates already containing $4 \mu \mathrm{g}$ of DNA plasmid. Culture media was replaced $6 \mathrm{~h}$ post transfection and cells were allowed to grow for $24 \mathrm{~h}$. Following incubation, media was changed and cells were selected with 2 mg/ml G418 (Gemini Bio-Products) for 2 weeks. Cells were trypsinized and seeded at low density allowing single colony formation. Single clones were selected and propagated for downstream analysis. pcDNA 3.1 plasmid was generously provided by Dr. Robert C. Cumming and 
$D D K-M Y C-m P D K 1$ overexpression construct was purchased from Origene.

\section{RNA isolation and quantitative reverse transcription-PCR analysis}

Total RNA, isolated at $72 \mathrm{~h}$ from cells using a RNeasy Mini kit (Qiagen), was reverse transcribed into first strand cDNA using the High-Capacity cDNA Reverse Transcription kit (Applied Biosystems). Quantitative reverse transcription-PCR (qRT-PCR) reactions, containing 500 $\mathrm{nM}$ of each primer (Supplementary Table 1), SensiFAST SYBR Mix (FroggaBio), and cDNA, were carried out using a CFX Connect Real-Time PCR Detection System (BioRad). Results were analyzed using the comparative cycle threshold $\left(2^{-\Delta \Delta C t}\right)$ method with L14 serving as the internal control.

\section{Immunoblot analysis}

Protein lysates were harvested using RIPA buffer (10 $\mathrm{mM}$ Tris- $\mathrm{HCl} \mathrm{pH}$ 8.0, $1 \mathrm{mM}$ EDTA, $0.5 \mathrm{mM}$ EGTA, $1 \%$ Triton $\mathrm{X}-100,0.1 \%$ sodium deoxycholate, $0.1 \%$ SDS, and $140 \mathrm{mM} \mathrm{NaCl}$ ) supplemented with HALT $^{\mathrm{Tm}}$ protease cocktail inhibitor (Thermo Fisher Scientific). Protein concentrations were determined using a $\mathrm{DC}^{\mathrm{m}}$ Protein Assay (Bio-Rad) and 5-40 $\mu \mathrm{g}$ of lysates were prepared in 5X SDS loading buffer (300 mM Tris-Hcl pH 8.0, 10\% SDS, $20 \mathrm{mM}$ EDTA, $0.1 \%$ bromophenol blue, and 50\% glycerol) and $10 \% \beta$-mercaptoethanol. Proteins were separated on $5-15 \%$ polyacrylamide gels for $2 \mathrm{~h}$ at $100 \mathrm{~V}$ and then transferred onto polyvinylidene difluoride membranes (Bio-Rad) for $2 \mathrm{~h}$ at $250 \mathrm{~mA}$ and $4{ }^{\circ} \mathrm{C}$. Membranes were placed in Tris-buffered saline with $0.1 \%$ Tween-20 (TBS-T) containing 5\% w/v skim milk powder and shaken at room temperature for $30 \mathrm{~min}$. Membranes were then incubated overnight at $4{ }^{\circ} \mathrm{C}$ with a primary antibody (Supplementary Table 2). After extensive washing with TBS-T, membranes were incubated with secondary antibodies (Supplementary Table 2) for $2 \mathrm{~h}$ at room temperature and signals were detected using a Immobilon Classico Western HRP substrate (Millipore Sigma). Images were collected using a ChemiDoc ${ }^{\mathrm{mm}}$ Touch Imaging System (Bio-Rad); for densitometric analysis, images were analyzed using Image Lab $^{\text {tw }}$ (Bio-Rad).

\section{Karyotype analysis}

Early- and late-passage F9 cells were cultured on $0.1 \%$ gelatin-coated coverslips and allowed to reach $80 \%$ confluency. Cells were treated with $0.2 \mu \mathrm{g} / \mathrm{ml}$ colcemid (Cayman Chemical) for $2 \mathrm{~h}$ at $37^{\circ} \mathrm{C}$, followed by trypsinization and suspension in pre-warmed $0.075 \mathrm{M} \mathrm{KCl}$ solution for 20 mins at $37^{\circ} \mathrm{C}$. Cells were fixed in acetic acid-methanol solution and then transferred onto prechilled glass slides. Chromosomes were stained with 4',6- diamidino-2-phenylindole mounting media containing ProLong ${ }^{\text {Tx }}$ Gold Antifade Mountant and examined using an Axio Imager A1 microscope (Carl Zeiss). Thirty representative images were taken of each cell and chromosomes were counted manually for statistical analysis.

\section{Detection of mitochondrial ROS and membrane potential}

Mitochondrial ROS and membrane potential were detected using MitoSOX ${ }^{\mathrm{mi}}$ Red Mitochondrial Superoxide indicator (MitoSOX; Thermo Fisher Scientific) and Tetramethylrhodamine, methyl ester perchlorate (TMRM; Thermo Fisher Scientific), respectively. Briefly, cells were seeded onto $0.1 \%$ gelatin-coated plates and allowed to differentiate as described above. At $96 \mathrm{~h}$, cells were washed with phosphate-buffered saline and incubated with $100 \mathrm{nM}$ MitoSOX or TMRM for $30 \mathrm{~min}$ at $37^{\circ} \mathrm{C}$ and $5 \% \mathrm{CO}_{2}$. Images were captured on an Axio Observer A1 Inverted microscope (Carl Zeiss) equipped with a Retiga 1300 camera (QImaging). Relative fluorescence intensity was quantified using ImageJ $1.48 \mathrm{~V}$ software $(\mathrm{NIH})$.

\section{Measuring ATP levels, glucose uptake, and lactate production}

ATP levels were measured using a CellTiter-Glo ${ }^{\bullet}$ Luminescent Cell Viability Assay (Promega). Briefly, cells were cultured and differentiated as described above. At $72 \mathrm{~h}$, cells were trypsinized, suspended in $100 \mu \mathrm{l}$ of media, and added to a 96-well plate. After adding $100 \mu \mathrm{l}$ of CellTiter-Glo ${ }^{\circ}$ reagent, cells were lysed for $2 \mathrm{~min}$ and incubated for $10 \mathrm{~min}$ in the dark at room temperature. Luminance was recorded using a Modulus ${ }^{\mathrm{Tt}}$ II microplate multimode system (Promega) and an integration time of $1.0 \mathrm{~s}$. For glucose uptake and lactate production, cells were cultured and differentiated as above, and at $72 \mathrm{~h}$ media was removed and centrifuged at $4{ }^{\circ} \mathrm{C}$ for $10 \mathrm{~min}$ at 10,000 r.p.m. Media was analyzed for glucose and lactate using a BioProfile 400 Chemical Analyzer (Nova Biomedical) at GCRC Metabolomics Core Facility (McGill University). Protein concentration was used to normalize values.

\section{Cytotoxicity assay}

F9 cells were cultured in $0,2,4$, and $6 \mathrm{mM}$ dichloroacetate (DCA) and assayed for viability using a MTT (3(4,5-dimethylthiazol-2-yl)-2,5-diphenyltetrazolium bromide) assay (Sigma). Briefly, media was removed $24 \mathrm{~h}$ post treatment and MTT reagent was added to cells cultured for $6 \mathrm{~h}$ at $37^{\circ} \mathrm{C}$ and $5 \% \mathrm{CO}_{2}$. To dissolve formazan crystals, DMSO was added to cells, which were shaken in the dark overnight at room temperature. Absorbance values at $570 \mathrm{nM}$ with a reference wavelength at $650 \mathrm{nM}$ were collected using the Modulus $^{\text {Tix }}$ II microplate system described above. 


\section{Scanning electron microscopy}

F9 cells were cultured and differentiated as mentioned above. Briefly, cells were washed in $0.1 \mathrm{M}$ phosphate buffer and fixed with $2 \%$ glutaraldehyde for 30 mins, followed by osmium tetroxide for $2 \mathrm{~h}$ at $4{ }^{\circ} \mathrm{C}$. After fixation, cells were dehydrated in a graded series of ethanol (50, 50, $75,85,95$, and $100 \%$ ) for 5 min each. Samples were airdried and sputter-coated with gold particles for 10 mins. Samples were viewed and images collected on a Hitachi S$3400 \mathrm{~N}$ microscope.

\section{Statistical analysis}

All values are presented as mean $\pm \mathrm{SEM}$ from at least three biological replicates. Comparisons between two groups were done using a Student's $t$-test. Comparisons between three or more groups were done using a one-way analysis of variance (ANOVA) followed by a Tukey's honest significant difference test. Chromosomal distribution frequency was tested by $\chi^{2}$-test for the Goodness of Fit. All data analyses were conducted using SPSS (Version 21.0, IBM Corp.) and graphs were generated using Prism software (Version 7.0d, 2017). $P$-values were considered significant at $" P<0.05, " P<0.01,{ }^{* \prime \prime \prime "} P<0.001$.

\section{Acknowledgements \\ This study was supported by a Discovery Grant (R2615A02) for operating funds grants from the Natural Sciences and Engineering Research Council of Canada (NSERC) to G.M.K. M.I.G. acknowledges support from the Faculty of Graduate and Postdoctoral Studies, University of Western Ontario, the Collaborative Graduate Specialization in Developmental Biology, University of Western Ontario, the Child Health Research Institute and NSERC for a CGS D scholarship. We also acknowledge the assistance from the GCRC Metabolomics core facilities, which is supported by grants from the Canadian Foundation for Innovation, Canadian Institutes of Health Research, and Terry Fox Research Institute, Finally, we thank Drs Dean H. Betts, Robert C. Cumming, and Lina Dagnino, and members of their labs and ours for resources and discussions over the course of this study.}

\section{Author details}

'Department of Biology, Collaborative Graduate Specialization in Developmental Biology, The University of Western Ontario, London, ON, Canada. ${ }^{2}$ Department of Paediatrics, The University of Western Ontario, London, ON, Canada. ${ }^{3}$ Department of Physiology and Pharmacology, The University of Western Ontario, London, ON, Canada. ${ }^{4}$ Child Health Research Institute, London, ON, Canada. ${ }^{5}$ Ontario Institute for Regenerative Medicine, Toronto, ON, Canada

\section{Conflict of interest}

The authors declare that they have no conflict of interest.

\section{Publisher's note}

Springer Nature remains neutral with regard to jurisdictional claims in published maps and institutional affiliations.

The online version of this article (https://doi.org/10.1038/s41420-018-0102-1) contains supplementary material, which is available to authorized users.

Received: 20 August 2018 Revised: 20 August 2018 Accepted: 28 August 2018

Published online: 26 September 2018

\section{References}

1. Ito, K. \& Ito, K. Metabolism and the control of cell fate decisions and stem cell renewal. Annu. Rev. Cell. Dev. Biol. 32, 399-409 (2016).

2. Ito, K. \& Suda, T. Metabolic requirements for the maintenance of self-renewing stem cells. Nat. Rev. Mol. Cell Biol. 15, 243-256 (2014).

3. Mathieu, J. \& Ruohola-Baker, H. Metabolic remodeling during the loss and acquisition of pluripotency. Development 144, 541-551 (2017).

4. Moussaieff, A., Kogan, N. M. \& Aberdam, D. Concise review: energy metabolites: key mediators of the epigenetic state of pluripotency. Stem Cells 33 2374-2380 (2015).

5. Ryall, J. G., Cliff, T., Dalton, S. \& Sartorelli, V. Metabolic reprogramming of stem cell epigenetics. Cell. Stem. Cell. 17, 651-662 (2015).

6. Shyh-Chang, N. \& Ng, H. H. The metabolic programming of stem cells. Genes Dev. 31, 336-346 (2017).

7. Warburg, O. On the origin of cancer cells. Science 123, 309-314 (1956).

8. Hanahan, D. \& Weinberg, R. A. Hallmarks of cancer: the next generation. Cell 144, 646-674 (2011).

9. Pavlova, N. N. \& Thompson, C. B. The emerging hallmarks of cancer metabolism. Cell. Metab. 23, 27-47 (2016).

10. Burgess, R. J., Agathocleous, M. \& Morrison, S. J. Metabolic regulation of stem cell function. J. Intern. Med. 276, 12-24 (2014).

11. Chandel, N. S., Jasper, H., Ho, T. T. \& Passegue, E. Metabolic regulation of stem cell function in tissue homeostasis and organismal ageing. Nat. Cell Biol. 18, 823-832 (2016).

12. Newsholme, E. A., Crabtree, B. \& Ardawi, M. S. The role of high rates of glycolysis and glutamine utilization in rapidly dividing cells. Biosci. Rep. $\mathbf{5}$ 393-400 (1985).

13. Folmes, C. D. \& Terzic, A. Metabolic determinants of embryonic development and stem cell fate. Reprod. Fertil. Dev. 27, 82-88 (2014).

14. Biggers, J. D., Whittingham, D. G. \& Donahue, R. P. The pattern of energy metabolism in the mouse oocyte and zygote. Proc. Natl Acad. Sci. USA 58, 560-567 (1967).

15. Kaneko, K. J. Metabolism of preimplantation embryo development: a bystander or an active participant? Curr. Top. Dev. Biol. 120, 259-310 (2016).

16. Zhou, W. et al. HIFla induced switch from bivalent to exclusively glycolytic metabolism during ESC-to-EpiSC/hESC transition. EMBO J. 31, 2103-2116 (2012).

17. Sperber, $\mathrm{H}$. et al. The metabolome regulates the epigenetic landscape during naive-to-primed human embryonic stem cell transition. Nat. Cell Biol. 17, 1523-1535 (2015).

18. Houghton, F. D., Thompson, J. G., Kennedy, C. J. \& Leese, H. J. Oxygen consumption and energy metabolism of the early mouse embryo. Mol. Reprod. Dev. 44, 476-485 (1996).

19. Kelly, G. M. \& Gatie, M. I. Mechanisms regulating stemness and differentiation in embryonal carcinoma cells. Stem Cells Int. 2017, 3684178 (2017).

20. Strickland, S. \& Mahdavi, V. The induction of differentiation in teratocarcinoma stem cells by retinoic acid. Cell 15, 393-403 (1978).

21. Strickland, S., Smith, K. K. \& Marotti, K. R. Hormonal induction of differentiation in teratocarcinoma stem cells: generation of parietal endoderm by retinoic acid and dibutyryl cAMP. Cell 21, 347-355 (1980).

22. Dickson, B. J., Gatie, M. I., Spice, D. M. \& Kelly, G. M. NOX1 and NOX4 are required for the differentiation of mouse F9 cells into extraembryonic endoderm. PLOS ONE 12, e0170812 (2017)

23. Wen, J. W., Hwang, J. T. \& Kelly, G. M. Reactive oxygen species and Wnt signalling crosstalk patterns mouse extraembryonic endoderm. Cell. Signal. 24, 2337-2348 (2012)

24. Sandieson, L., Hwang, J. T. \& Kelly, G. M. Redox regulation of canonical Wnt signaling affects extraembryonic endoderm formation. Stem. Cells Dev. 23, 1037-1049 (2014).

25. Folmes, C. D. et al. Somatic oxidative bioenergetics transitions into pluripotency-dependent glycolysis to facilitate nuclear reprogramming. Cell. Metab. 14, 264-271 (2011).

26. Panopoulos, A. D. et al. The metabolome of induced pluripotent stem cells reveals metabolic changes occurring in somatic cell reprogramming. Cell Res. 22, 168-177 (2012).

27. Varum, S. et al. Energy metabolism in human pluripotent stem cells and their differentiated counterparts. PLOS ONE 6, e20914 (2011).

28. Chin, M. H. et al. Induced pluripotent stem cells and embryonic stem cells are distinguished by gene expression signatures. Cell. Stem. Cell. 5, 111-123 (2009).

29. Kim, K. et al. Epigenetic memory in induced pluripotent stem cells. Nature 467, 285-290 (2010). 
30. Polo, J. M. et al. Cell type of origin influences the molecular and functional properties of mouse induced pluripotent stem cells. Nat. Biotechnol. 28, 848-855 (2010).

31. Liu, X. et al. Trisomy eight in ES cells is a common potential problem in gene targeting and interferes with germ line transmission. Dev. Dyn. 209, 85-91 (1997).

32. Longo, L., Bygrave, A., Grosveld, F. G. \& Pandolfi, P. P. The chromosome makeup of mouse embryonic stem cells is predictive of somatic and germ cell chimaerism. Transgenic. Res. 6, 321-328 (1997).

33. Gaztelumendi, N. \& Nogues, C. Chromosome instability in mouse embryonic stem cells. Sci. Rep. 4, 5324 (2014).

34. Dobrovolny, P. L. \& Bess, D. Optimized PCR-based detection of mycoplasma. J. Vis. Exp. pii: 3057 (2011).

35. Tonack, S., Rolletschek, A., Wobus, A. M., Fischer, B. \& Santos, A. N. Differential expression of glucose transporter isoforms during embryonic stem cell differentiation. Differentiation 74, 499-509 (2006).

36. Liu, P. et al. Passage number is a major contributor to genomic structural variations in mouse iPSCs. Stem Cells 32, 2657-2667 (2014).

37. Lee, K. S. et al. Effects of serial passage on the characteristics and chondrogenic differentiation of canine umbilical cord matrix derived mesenchymal stem cells. Asian Australas. J. Anim. Sci. 26, 588-595 (2013).

38. Izadpanah, R. et al. Long-term in vitro expansion alters the biology of adult mesenchymal stem cells. Cancer Res. 68, 4229-4238 (2008).

39. Kretlow, J. D. et al. Donor age and cell passage affects differentiation potential of murine bone marrow-derived stem cells. BMC Cell. Biol. 9, 60 (2008).

40. Jiang, $T$. et al. In vitro expansion impaired the stemness of early passage mesenchymal stem cells for treatment of cartilage defects. Cell Death Dis. 8 , e2851 (2017).

41. Rupprecht, A. et al. Uncoupling protein 2 and 4 expression pattern during stem cell differentiation provides new insight into their putative function. PLOS ONE. 9, e88474 (2014)

42. Zhang, J. et al. UCP2 regulates energy metabolism and differentiation potential of human pluripotent stem cells. EMBO J. 30, 4860-4873 (2011).

43. Liu, J., Kim, J. \& Oberdoerffer, P. Metabolic modulation of chromatin: implications for DNA repair and genomic integrity. Front. Genet. 4, 182 (2013).

44. Garitaonandia, I. et al. Increased risk of genetic and epigenetic instability in human embryonic stem cells associated with specific culture conditions. PLoS ONE 10, e0118307 (2015).

45. Bartesaghi, S. et al. Inhibition of oxidative metabolism leads to p53 genetic inactivation and transformation in neural stem cells. Proc. Natl Acad. Sci. USA 112, 1059-1064 (2015).

46. Williams, B. R. et al. Aneuploidy affects proliferation and spontaneous immortalization in mammalian cells. Science 322, 703-709 (2008).

47. Gu, Y. et al. Changes in mesenchymal stem cells following long-term culture in vitro. Mol. Med. Rep. 13, 5207-5215 (2016).
48. Shum, L. C., White, N. S., Mills, B. N., Bentley, K. L. \& Eliseev, R. A. Energy metabolism in mesenchymal stem cells during osteogenic differentiation. Stem. Cells Dev. 25, 114-122 (2016).

49. Peng, M. et al. Aerobic glycolysis promotes $T$ helper 1 cell differentiation through an epigenetic mechanism. Science 354, 481-484 (2016).

50. Price, M. J., Patterson, D. G., Scharer, C. D. \& Boss, J. M. Progressive upregulation of oxidative metabolism facilitates plasmablast differentiation to a Tindependent antigen. Cell Rep. 23, 3152-3159 (2018).

51. Spinelli, J. B. \& Haigis, M. C. The multifaceted contributions of mitochondria to cellular metabolism. Nat. Cell Biol. 20, 745-754 (2018).

52. Rossignol, R. et al. Energy substrate modulates mitochondrial structure and oxidative capacity in cancer cells. Cancer Res. 64, 985-993 (2004).

53. Bratic, I. \& Trifunovic, A. Mitochondrial energy metabolism and ageing. Biochim. Biophys. Acta 1797, 961-967 (2010).

54. Hansson, J. et al. Highly coordinated proteome dynamics during reprogramming of somatic cells to pluripotency. Cell Rep. 2, 1579-1592 (2012).

55. Westermann, B. Bioenergetic role of mitochondrial fusion and fission. Biochim. Biophys. Acta 1817, 1833-1838 (2012).

56. Xie, X. et al. Effects of long-term culture on human embryonic stem cell aging. Stem. Cells Dev. 20, 127-138 (2011).

57. Koehler, K. R. et al. Extended passaging increases the efficiency of neural differentiation from induced pluripotent stem cells. BMC Neurosci. 12, 82 (2011).

58. Gao, P. \& Malbon, C. C. Differentiation of F9 teratocarcinoma stem cells to primitive endoderm is regulated by the Gialpha2/Gsalpha axis via phospholipase C and not adenylylcyclase. J. Biol. Chem. 271, 30692-30698 (1996).

59. Futaki, S., Hayashi, Y., Emoto, T., Weber, C. N. \& Sekiguchi, K. Sox7 plays crucial roles in parietal endoderm differentiation in F9 embryonal carcinoma cells through regulating Gata-4 and Gata-6 expression. Mol. Cell. Biol. 24, 10492-10503 (2004)

60. Verheijen, M. H., Wolthuis, R. M., Bos, J. L. \& Defize, L. H. The Ras/Erk pathway induces primitive endoderm but prevents parietal endoderm differentiation of F9 embryonal carcinoma cells. J. Biol. Chem. 274, 1487-1494 (1999).

61. Krawetz, R. \& Kelly, G. M. Wnt6 induces the specification and epithelialization of F9 embryonal carcinoma cells to primitive endoderm. Cell. Signal. 20, 506-517 (2008)

62. Krawetz, R. \& Kelly, G. M. Coordinate Galpha13 and Wnt6-beta-catenin signaling in F9 embryonal carcinoma cells is required for primitive endoderm differentiation. Biochem. Cell. Biol. 87, 567-580 (2009).

63. Mendoza-Parra, M. A., Walia, M., Sankar, M. \& Gronemeyer, H. Dissecting the retinoid-induced differentiation of F9 embryonal stem cells by integrative genomics. Mol. Syst. Biol. 7, 538 (2011). 